\title{
Overview Of Youth and Violence
}

Simarpreet Kaur

Assistant Professor, ECE Deptt., BBSBEC, Fatehgarh Sahib

\begin{abstract}
In this paper, an overview of four key questions are addressed: 1) Are today's youth really more violent? 2) How many youth are victims of violence or committing violent acts themselves? 3) What are the major causes of youth violence? and 4) What is known about the prevention and control of youth violence?
\end{abstract}

Indexing terms/Keywords

Violence, Youth.

\section{Academic Discipline And Sub-Disciplines}

Psychology; behavioural sciences;

\section{SUBJECT CLASSIFICATION}

Social Conditions in India;

\section{TYPE (METHOD/APPROACH)}

Literary Analysis

\section{Council for Innovative Research}

\author{
Peer Review Research Publishing System
}

Journal: Journal of social Science Research

\author{
Vol 1, No 3 \\ editor@cirworld.com \\ www.cirworld.com, member.cirworld.com
}

INTRODUCTION Across the globe, people are scared these days because residents of affluent suburban communities, and even small towns and rural areas face the violence epidemic which signals a general breakdown in the 
social order. There seem to be no safe places; the violence extends into our homes, neighbourhoods, schools, day care facilities, shopping malls, and workplaces. The perpetrators are often relatives, friends or acquaintances of the victim. So much of the violence seems petty, senseless or random, suggesting a wanton disregard for human life. And both perpetrators and victims are increasingly our adolescents and children.

In this paper, an overview of four key questions are addressed: 1) Are today's youth really more violent? 2) How many youth are victims of violence or committing violent acts themselves? 3) What are the major causes of youth violence? and 4) What is known about the prevention and control of youth violence?

It is also a fact that violence now sweeping across the globe gets more and more pronounced with each passing day as human society takes long stride towards "Development and Progress". India's message, with all her diversities to the world has been Sarva Dharma Sambhava, a nationality founded on the basis of universal peace. The mind of India has for centuries been able to receive and absorb the new without a violation of its root or direction. But today, as the $21 \mathrm{st}$ century unfolds before us, it is not the loss of idealism alone that is disturbing. That loss could have been made up to a great extent by the dynamism of the young [1].

\section{Whither our youth today?}

This is a question uppermost in everyone's mind. It is deplorable that some of our youth in their ignorance are attracted by the culture of violence. One hears on all sides that the youth is in revolt. Many of us have a good deal of sympathy with this attitude if revolt, the one complaint we have is that it is not sufficiently widespread. The general tendency to regard our ancient civilization as idealistic and the modern one as materialistic is not the expression of revolt but of reaction.

After passing through rapid zigzags during the past quarter century, the world youth scene has shifted, as if to a plateau. If the youth does not come forward to help the nation in crisis, history will look askance at them. Injustice thrives on the difference of the people. Youth is active in certain pockets but in a negative sense. They have allowed themselves to be the willing tools in the hands of certain misguided elements who are using them to realise their own ends. Whether in Punjab, Kashmir, or Sri Lanka, or the Taliban in Afghanistan, it is the same story.

Why do the youth get lured on the wrong path and take to violence?

What is that which helps to create the terrorist personality, the terrorist ethos and the terrorist World view? The youth must ponder over these questions in search of plausible answers for in these answers lies the chances of a misguided youth's journey back to sanity.

Psychologists have from time to time advanced certain theories to explain the working of the terrorist mind. Lawrence Zelic Freedman in a recent anthology entitled 'Perspectives on Terrorism' for instance offers four hypotheses in this regard.

1. The Affirmation of self-esteem', particularly where an ego has been deeply hurt and denied identity.

2. Depersonalization i.e. the surrender of one's personality in the service of a group to escape the terrible burden of human responsibility.

3. Terrorism as a" method of establishing intimacy" that is to say, it's a means to enforce recognition and thus establish a subjective relationship with one's victim and

4. A belief in the magic of violence, wherein the elements of secrecy, mystery, wonder and sacrament fuse to propel the terrorists toward an unknown territory.

To this list, may be added terrorism as 'game' as big business link up and political nexus with the underworld and the local mafia and a quick means to make a quick buck above all the lure of sheer (mis) adventure.

What is the root cause of growing conflicts?

Different reasons underlie the rural and urban violence. The reasons are various. The failure to implement the reform laws, the courts of law where the procedures and costs of justice have conspired to deny a fair deal to the weaker sections of our society and the system of education producing an ever expanding army of ill-educated, frustrated unemployed youth. The Universities have failed to arouse a sense of national fervour and purpose in the life and minds of the young. They have become an agency for distributing degrees, which is in most cases nit even worth the paper they are printed on. But while all this is understandable it is relevant to ask, if violence will prove to be the saviour it is promised to be? No it won't. Today we find that there is an all round drift in our society.

Youth rebellion is held out to be basically a reflection of the growing gulf between the young and the old The old are seen not merely as out-of-date but also as hypocritical Youth finds the world in a mess and blames older generation for it The latter are not exactly models deserving of emulation by the young.

In a span of fifty-four years of achieving Independence, there has been marked change in the character of leadership in the social and political fields In the pre-independence period youth was in the national movement; the leaders were 'accepted'. Today we find that leaders in almost every walk of public life have lost the respect of the young In this land of the Buddha and Gandhi, we are today, after 54 years of independence, surrounded by violence of thought, word and deed.

\section{Are Today's Youth More Violent and Victimized by Violence?}

Is the current violence "epidemic" a distortion resulting from excesses in media coverage or does it reflect a real change in the behaviour of youth? The evidence suggests the following conclusions about trends in youth violence over the past 
decade: 1) There is a substantial increase in the violence victimization rates for adolescents, particularly for 12-15 year olds; 2) There has been a relatively small increase in the proportion of adolescents involved in some type of serious violent offending; and 3) There has been a dramatic increase in adolescent homicide rates.

Today's youth are more frequently the victims of violence; but about the same proportion of youth are committing serious violent offenses like aggravated assaults, forcible rapes, robberies, and homicides and their frequency of offending is approximately the same. One important dimension of youth violence has clearly changed. Today's violent acts are more lethal, a larger proportion of these acts result in serious injury or death. And this dramatic increase in the lethality of adolescent violence is entirely by the increased use of handguns in these violent exchanges like the shootout by a school student of his classmates in USA.

\section{How Many Youth Are Serious Violent Offenders or Victims?}

The age of highest risk for the initiation of serious violent behaviour is age 15-16 and that the risk of initiating violence after age 20 is very low. If persons have not initiated serious violent behaviour by age 20 , it is unlikely that they will ever become serious violent offenders. The highest rates of participation in serious violence are at ages 16-17. At these ages, 20-25 percent of males and 4-10 percent of females report one or more serious violent acts. After age 17 however, participation rates drop dramatically. Approximately 80 percent of those who were violent during their adolescent years will terminate their violence by age 21 .

Estimates of physical abuse of children and youth suggest that as many as 10 percent are assaulted by family members and caregivers each year. Among children and youth, preschoolers were most likely to be victims of physical assault, followed by elementary school-aged children, teenagers, and infants. Children under age 4 are more likely to be killed than older children. Infants are more often killed by their mothers than fathers. Between 2-4 percent of youth are victims of a violent personal assault each year while at school. Overall, teenagers are twice as likely to be victims of an assault as persons aged twenty and older. Suicide is now the third leading cause of death for youth. Clearly our children and teenagers are the most frequent victims of violence [2].

Young violent offenders and victims have similar personal characteristics. This is because many youthful victims of violence are also involved in violent behaviour themselves, or are at high risk of becoming violent during their adolescent years. While both offenders and victims are disproportionately male, black, urban, and from low income and single-parent families, this characterization of violent youth is misleading. Among children, the gender difference in victimization is small, whereas among adolescent victims and violent offenders, it is quite strong. Among violent offenders, race/ethnic and social class differences are small during adolescence; they become substantially greater during the adult years. Youth violence is thus very widespread in our society. It is not just a problem for the poor, or minorities, or those in our large cities. It crosses all class, races \& genders.

\section{What are the Major Causes of Youth Violence?}

Most violent behaviour is learned behaviour. We all have some potential for violent behaviour; we have observed others using violence and know how to do it. But while it may be a part of nearly everyone's behavioural repertoire, most persons have non-violent ways of achieving their purposes which are effective in most situations. Further, their commitment to conventional norms and values inhibits their use of violent behaviour and they are embedded in social networks (family and friends) and situations where this type of behaviour would have serious negative ramifications. Under these circumstances, violent behaviour becomes irrational.

Unfortunately, for too many youth, violence is either the only or the most effective way to achieve status, respect, and other basic social and personal needs. Like money and knowledge, violence is a form of power, and for some youth, it is the only form of power available. When such limited alternatives are combined with a weak commitment to moral norms (internal controls) and little monitoring or supervision of behaviour (external controls), violent behaviour becomes rational. The potential rewards are great, the perceived costs minimal.

\section{The Family Context}

The initial causes of violence are found in the early learning experiences in the family. They involve 1) weak family bonding, ineffective monitoring and supervision; 2) exposure to and reinforcement for violence in the home, and 3) the acquisition of expectations, attitudes, beliefs and emotional responses which support or tolerate the use of violence.

Early exposure to violence in the family may involve either witnessing violence or physical abuse i.e. exposure to violence during childhood increase the risk of violent behaviour during adolescence by as much as 40 percent. Still, most youth who are victims of physical abuse do not go on to become serious violent offenders. While exposure to real violence and physical abuse on the part of family members have stronger modelling effects, heavy exposure to violence on television and video games is also causally linked to later violence. In many homes, television \& video games is the de facto babysitter, with little or no monitoring or supervision of content. When there is strong family bonding, effective teaching of moral values and norms, and effective monitoring of behaviour, the effect of exposure to violence on TV /video games is probably negligible; without this protection, its effect can be quite strong. What is learned is not only how to do violence, but desensitization to violence and rationalizations for disengaging one's moral obligations to others. 
Families with the high risk for child abuse are those with parents or caretakers who have limited problem solving skills, poor impulse control and a history of violent behaviour during adolescence. These caretakers are frequently young, low income, single parent, minority women with four or more children in the household. Fathers, when present, tend to be parttime employed and have a limited education. These families have few resources and are experiencing both social isolation and economic stress. They have few alternatives and limited social supports from extended family or friendship networks which might provide social controls on their behaviour and non-violent alternatives for managing their children.

\section{The Neighbourhood Context}

Some neighbourhoods also provide opportunities for learning and engaging in violence. The presence of gangs and illegal markets, particularly drug distribution networks, not only provide high levels of exposure to violence, but violent role models, and positive rewards for serious violent activity. Single parent families, ineffective parenting, violent schools, high dropout rates, high adolescent pregnancy rates, substance abuse and high unemployment rates are all concentrated in such neighbourhoods.

While these neighbourhoods are areas with high rates of concentrated poverty, the critical feature of such neighbourhoods that is most directly related to the high rates of violence, crime and substance use, is the absence of any effective social or cultural organization in these neighbourhoods. High levels of transiency make it difficult to establish common values and norms, informal support networks and effective social controls. High chronic unemployment results in social isolation from legitimate labor markets, and undermines the relevance of completing school. Illegitimate enterprises and gangs emerge in these neighbourhoods, in part because the neighbourhood has no effective means of resisting such activity, and in part as a means of providing some stable social organization for youth and some economy for the neighbourhood. Not all poor neighbourhoods are disorganized however; and those that are effectively organized have low rates of violent behaviour, crime and substance use. Poverty is linked to violence through disorganized neighbourhoods.

The effect of living in such neighbourhoods can be devastating on the family's attempt to provide a healthy, conventional upbringing for their children. Not only are there few social reinforcements for conventional lifestyles to support this type of parenting, but conventional opportunities are limited by racism, discrimination, social isolation from the labor market and few resources. There are often greater opportunities for participation in gangs and the illicit economy which offer relatively quick and substantial rewards that seem to offset the risks associated with violence. One effect of participation in these types of activities is that youth are at high risk for becoming victims.

\section{The School and Peer Context}

Patterns of behaviour learned in early childhood (e.g., aggressiveness) carry over into the school context, the school has its own potential for generating conflict and frustration and violent responses to these situations. A successful non-violent social adjustment at home increases the likelihood but does not guarantee a successful non-violent adjustment to school and peers. These are new social systems which have to be negotiated, where one must find her or his own niche. They each have their own performance demands and developmental tasks to complete. Failure to meet these school and peer performance expectations (e.g., academic success, peer approval, personal competence and independence, self-efficacy, and a capacity for developing and maintaining interpersonal relationships and intimacy) creates stress and conflict. The combination of new conflicts and reduced levels of monitoring and supervision in these contexts increases the likelihood that violence will emerge in response to these problems.

During junior and senior high school, a clear adolescent status hierarchy emerges, and much of the violence at school is related to competition for status and status-related confrontations. Ability tracking also contributes to a collective adaptation to school failure and peer rejection by grouping academically poor students and those who are aggressive troublemakers together in the same classes. Delinquent peer groups tend to emerge out of these classes and individual feelings of anger, rejection and alienation are mutually reinforced in these groups. The strongest and most immediate cause of the actual onset of serious violent behaviour is involvement with a delinquent peer group. It is here that violence is modelled, encouraged, and rewarded; and justifications for disengaging one's moral obligation to others are taught and reinforced. The effects of early exposure to violence, weak internal and family controls and aggressive behaviour patterns developed in childhood all influence the type of friends one chooses, and the type of friends, in turn, largely determines what behaviour patterns will be modelled, established and reinforced during adolescence. However, a strong bond to parents is a protective factor which insulates youth from the influence of delinquent friends as long as the friendship network is not dominated by such youth.

Gangs are a subtype of adolescent peer group, with a more formal identity and membership requirements. They tend to involve more homogeneously delinquent youth, often actively recruiting persons for their fighting skills or street smarts. In some instances membership entails violent behaviour as an initiation ritual. However, not all gangs are involved in serious violent behaviour or drug distribution. They often serve some positive functions, particularly in disorganized neighbourhoods. They not only provide youth a sense of acceptance, belonging and personal worth (which most friendships do), but also a safe place to stay, food, clothing and protection from abusive parents. But like delinquent groups more generally, joining a gang greatly increases the risk of serious violence, both perpetration and victimization. Likewise, leaving a gang or delinquent peer group substantially reduces the risk of serious violence.

\section{Alcohol, Illicit Drugs and Firearms}

The reationship between substance use and violence is complicated. Alcohol is implicated in over half of all homicides and of assaults in the home. Parents who abuse alcohol (and illicit drugs) are more prone to be physically abusive and 
neglectful of their children. But while problem drinkers are more likely to have a history of violent behaviour, they are not disproportionately represented among violent offenders as compared to non-violent offenders [4]. In general, the use of psychoactive drugs has not been linked pharmacologically to violent behaviour. The effect of marijuana and opiate drugs actually appears to inhibit violence, although withdrawal may precipitate an increased risk of violence. There is some evidence that drug addicts commit violent crimes to support their drug habit, but this appears to be a relatively rare phenomenon. The clearest drug-violence connection is for selling drugs; the drug distribution network is extremely violent. Not much is known about why today's youth, in increasing numbers, are carrying guns. Anecdotal evidence suggests it is to "show off", to insure "respect" and acquiescence from others, or for self-defence. In part, it appears to be a response to the perception that public authorities cannot protect youth or maintain order in their neighbourhoods or at school. There is evidence that dropouts, drug dealers and those with a prior record of violent behaviour are more likely to own a gun than are other adolescents. And the vast majority (80 percent) of firearms used in crimes are obtained by theft or some other illegal means [5].

\section{The Adolescence-Adulthood Transition}

The successful transition into adult roles (work, marriage, parenting) appears to reduce involvement in violent behaviour. In one national study, nearly 80 percent of adolescents who were serious violent offenders reported no serious violent offenses during their adult years (to age 30). However, nearly twice as many black as white youth continued their offending after age 21 . Among those employed at age 21 , rates of continuity were low and there were no differences in rates of continuity by race [7].

It appears that growing up in poor, minority families and disorganized neighbourhoods has two major effects directly related to violent behaviour. First, when it comes time to make the transition into adulthood, there are limited opportunities for employment which, in turn, reduces the chances of marriage. These are two primary definers of adult status. Second, there is evidence that growing up in poor, disorganized neighbourhoods inhibits a normal course of adolescent development. Youth from these neighbourhoods have lower levels of personal competence, self-efficacy, social skills, and self-discipline. Many are not adequately prepared to enter the labour market even if jobs were available. They are, in some ways, trapped in an extended adolescence and continue to engage in adolescent behaviour.

\section{What is known About the Prevention and Control of Youth Violence?}

Since most violent behaviour is learned behaviour, the general strategy for prevention and treatment interventions should be 1) to reduce the modelling and reinforcement of violence as a means of solving problems and manipulating or controlling the behaviour of others and 2) to ameliorate those social conditions which generate and support violent lifestyles. The most effective strategy for accomplishing this is to insure a healthy course of child and adolescent development for all youth, so they are prepared to enter productive, responsible adult roles; and to insure that these roles are accessible [6].

\section{Promote a safe and supportive home environment}

Increase the capacity of parents and/or caregivers to raise nonviolent youth., assure and promote alcohol and chemical dependency treatment for parents, support and facilitate help-seeking where family violence occurs, educate about the benefits and ways of restricting exposure to violent media, promote connectedness between family members and the community.

\section{Work with schools to proactively prevent violence}

Fully implement evidence-based youth violence prevention programs, promote on-site screening and intervention, including mental health services for trauma, loss, use of alcohol and other drugs, and abuse, Intervene early with students with multiple risk factors for violence and Create school climates that foster a sense of inclusivity and belonging among students.

\section{Organize the community to reduce risks and increase protective factors}

Strategically engage in youth development approaches, provide youth with opportunities to discuss and develop healthy intimate relationships, Reduce access to alcohol, reduce the proportion of persons living in homes with firearms that are loaded and unlocked, strengthen community standards against violence, harassment, aggression, racism, sexism, heterosexism and bullying.

\section{Do not carry a gun or other weapons. Carrying a gun will not make you safer.}

Guns often escalate conflicts and increase the chances that you will be seriously harmed. If someone is threatening you and you feel that you are in serious danger, do not take matters into your own hands. Find an adult you can trust and discuss your fears, or contact school administrators or the police. Take precautions for your safety, such as avoiding being alone and staying with a group of friends if possible.

\section{If you know someone is planning to harm someone else - report him or her.}

Most of us have learned from an early age that it is wrong to tattle, but in some instances it is the most courageous 
thing you can do. Tell a trusted adult, such as a teacher, guidance counselor, principal or parent. If you are afraid and believe that telling will put you in danger or lead to retaliation, find a way to anonymously contact the authorities.

\section{Advocate with systems to address social conditions and improve system practices related to violence}

Advocate for policy initiatives to meet basic family support needs including income, housing, food and nutrition, prenatal and childcare,rain professionals to recognize and respond to violence, and to refer individuals for support, decrease institutional racism and heterosexism, and promote cultural respect, inclusivity and competency, endorse and promote a comprehensive package of preventive health services for youth ages 11 to 21 , advocate for funding to expand financing and reimbursement for preventive and primary adolescent health services, ensure safe housing and neighborhoods and provide housing and care for all youth who cannot live at home [8].

\section{Conclusion}

Youth violence is a complex public health problem with many risk factors, including individual beliefs and behaviors such as early aggression and use of alcohol or other drugs; family characteristics such as spousal abuse and lack of parental supervision; peer and school influences such as associating with delinquent friends; and environmental factors such as access to firearms. This complexity presents many challenges for those who are working to prevent youth violence [3]. There may be lots of youth violence. In these violence, we can include to abuse each other, beating, killing anybody, attack on anybody. To stop youth violence is very necessary. Without knowing the reason, we can not stop youth violence. Adolescents After knowing the reason of violence, we have to give good motivation for stopping these violence. There is big role of parent to leave youth violence. Why are youths so cruel? Because their parent do not care their children. Their children learns violence from bad society. Due to this, they started to fight without any reason. So, it is the duty of parents to teach their children. Only after this, they can adopt non-violence. After getting the age of adult, some youths become very angry. They make gang and start to robbery for getting big money. Govt. should arrest all these youth and give big punishment. It is the duty of teacher to tell the benefits of non-violence. Knowledge of non-violence is the big knowledge. Only way to success in the life is non-violence and love with each religion. Even if we cannot do it all, it is important to make a beginning at once. Every step we take, guided by the findings of scientific research, will make a difference in young lives and in the quality of life for all people.

\section{REFERENCES}

[1] American Psychological Association Commission on Youth Violence. (1993). Violence and Youth: Psychology's Response. Washington, DC: American Psychological Association.

[2] Bureau of Justice Statistics. (1991). Teenage Victims. Washington, DC: U.S. Department of Justice.

[3] Dahlberg, LL.1998 Youth Violence in the United States: Major Trends, Risk Factors, and Prevention Approaches. American Journal of Preventive Medicine 14(4), 259-272.

[4] Elliott, D.S. 1994. Serious Violent Offenders: Onset, Developmental Course, and Termination: The American Society of Criminology 1993 Presidential Address. Criminology, 32(1), 1-22.

[5] Federal Bureau of Investigation. 1992. Crime in the United States, 1991. Washington, DC: U.S. Government Printing Office.

[6] Lipsey, M. 1991. The Effect of Treatment on Juvenile Delinquents: Results from Meta-Analysis. In F. Losel, D. Bender, \& T. Bliesener (Eds.), Psychology and Law. New York, NY: Walter de Gruyter.

[7] National Research Council. 1993. Losing Generations: Adolescents in High Risk Settings. Washington, DC: National Academy Press.

[8] National Research Council. 1993. Understanding and Preventing Violence. Washington, DC: National Academy Press. Osgood, D.W., O’Malley, P.M, Bachman, J. G., \& Johnston, L.D. 1989. Time Trends and Age Trends in Arrests and Self-Reported Illegal Behavior. Criminology, 27(3), 389-417. 


\section{Author' Biography}

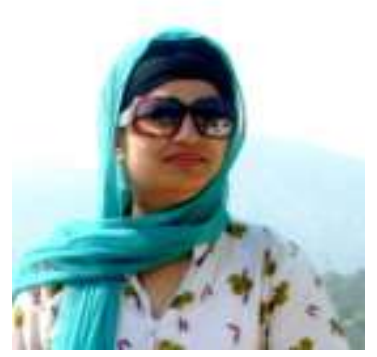

Simarpreet Kaur has received her M-Tech and B-Tech degrees from Punjab Technical University, India in 2008 and 2001, respectively. She has over 10 years of teaching experienc. She worked as a lecturer in Punjab Engineering College, Chandigarh, India for six years. She is currently working as an Assistant Professor in Baba Banda Singh Bahadur Engineering College, Fatehgarh Sahib, Punjab. She is guiding many M-Tech thesis. Her research interests are in the fields of Broadband communications, Wireless Sensor Networks and Social Sciences. She has 7 papers in National Conferences/Journals, 7 papers in International Conferences and 17 papers in International Journals. She has organized many FDPs and workshops in her college. 